\title{
Knowledge of results during vertical jump testing: an effective method to increase the performance but not the consistency of vertical jumps
}

\author{
Amador García-Ramos (ID ${ }^{\mathrm{a}, \mathrm{b}}$, Danica Janicijevic ${ }^{c}$, Juande Cobo-Font ${ }^{\mathrm{a}}$, Daniel Marcos- \\ Frutos $^{a}$, John F. T. Fernandes ${ }^{d}$, Wolfgang Taube ${ }^{\mathrm{e}}$ and Alejandro Pérez-Castilla (D) $^{\mathrm{a}}$ \\ aDepartment of Physical Education and Sport, Faculty of Sport Sciences, University of Granada, Granada,

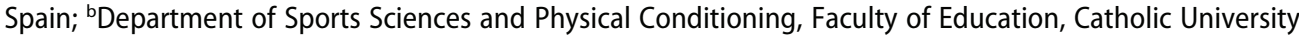 \\ of the Most Holy Conception, Concepción, Chile; 'Faculty of Sport and Physical Education, the Research \\ Centre, University of Belgrade, Belgrade, Serbia; 'Sport, Exercise and Well-being Arena, Hartpury University, \\ Hartpury, UK; eDepartment of Neurosciences and Movement Sciences, University of Fribourg, Fribourg, \\ Switzerland
}

\begin{abstract}
This study aimed to determine whether the provision of jump height feedback (knowledge of result; KR) can increase the performance and the consistency of output variables. In a randomised order, sixteen participants performed six squat or countermovement jumps (three from a $90^{\circ}$ knee angle and three from a selfpreferred knee angle) with or without KR over four sessions. The provision of KR significantly increased peak force ( $p=0.046,1.83 \%)$, mean force $(p=0.037,1.45 \%)$, peak velocity $(p<0.001,3.71 \%)$, mean velocity $(p=0.004,3.44 \%)$, peak power $(p<0.001,4.22 \%)$ and mean power $(p=0.001,4.69 \%)$. A high within-session reliability was observed for all variables (coefficient of variation [CV] $\leq 5.62 \%$, intraclass correlation coefficient $[I C C] \geq 0.95$ ). No systematic differences in reliability were detected between the jumps performed without $\mathrm{KR}(\mathrm{CV}=3.00 \pm 1.38 \%, \mathrm{ICC}=0.97 \pm 0.03)$ and with $\mathrm{KR}$ $(C V=3.04 \pm 1.49 \%$, ICC $=0.97 \pm 0.04)$. These results suggest that the provision of jump height feedback during vertical jump testing is effective to enhance vertical jump performance but it does not reduce the variability between jumps.
\end{abstract}

\section{KEYWORDS}

Countermovement jump force platform; jump height; reliability; squat jump

\section{Introduction}

Vertical jumps are commonly used to evaluate the function of lower-body muscles due to the high reliability, validity, and sensitivity of their outcomes (Mandic et al., 2015; Markovic et al., 2004). Commonly, force platforms are used in the scientific literature to evaluate vertical jump performance (Linthorne, 2001; Simpson et al., 2018; Vanrenterghem et al., 2004). An advantage of the force platform is that it not only provides data to calculate jump height, but also to compute other mechanical variables such as the mean and peak values of force, velocity, and power (Linthorne, 2001). Nonetheless, vertical jump testing procedures are primarily used to ascertain the 
individual's maximal jumping capacity. To achieve this goal, participants are instructed to jump with maximal effort while long rest periods are implemented between successive trials to minimise fatigue (Petronijevic et al., 2018; Vanderka et al., 2018). However, in addition to recording the maximal jumping performance, the reproducibility of the obtained outcomes during the test should be high (Hopkins, 2000b). Utilising a test procedure that has a high reliability is widely acknowledged and aids practitioners' confidence when monitoring changes in performance. Therefore, it is important to develop methodological guidelines that maximise both the magnitude and the reliability of the main outcome parameters collected during vertical jump testing procedures.

One methodological factor that should be considered during vertical jump testing procedures is the provision of augmented feedback. Knowledge of result (KR) is the most commonly used augmented feedback during vertical jump testing procedures. It has been reported that the provision of jump height feedback (i.e., KR) enhances short- and longterm vertical jump performance (Keller et al., 2015; Walchli et al., 2016) and was increases in motivation and competitiveness (Keller et al., 2015; Salmon et al., 1984). Therefore, given that one of the main goals of vertical jump testing procedures is to record the individual's maximal jumping capacity, it seems reasonable to provide KR after each trial. However, to our knowledge, no previous study has explored the effect of $\mathrm{KR}$ on the reliability of the main mechanical variables that can be collected with a force platform during the squat jump (SJ) and countermovement jump (CMJ) exercises (Randell et al., 2011b). Therefore, it would be of interest to elucidate whether the provision of KR could increase the reliability of vertical jump testing procedures because a high reliability is a fundamental requirement for any physical test (Hopkins, 2000b).

Another methodological factor that influences the magnitude and reliability of vertical jumps is the standardisation of the body position at the beginning of the propulsive phase (Argus \& Chapman, 2014; Kirby et al., 2011). The initial position has been commonly standardised at a fixed knee angle of $90^{\circ}$ (Duthie et al., 2002; Impellizzeri et al., 2007; Skurvydas et al., 2000). However, recent studies have suggested that a self-preferred starting position can be reliably used to simplify the vertical jump testing procedure (Janicijevic et al., 2019; Mitchell et al., 2017; Petronijevic et al., 2018). Of note is that participants only receive one instruction when they self-select the initial knee angle (e.g., 'jump as high as possible'), but two instructions when the initial position is standardised (e.g., 'meet a $90^{\circ}$ knee angle' and 'jump as high as possible'). Most of the studies that have compared the standardised and self-preferred initial positions have used the SJ since it is easier to strictly control the initial knee angle (Argus \& Chapman, 2014; Janicijevic et al., 2019; Mitchell et al., 2017; Petronijevic et al., 2018). For example, Janicijevic et al. (2019) showed that the mechanical outputs (i.e., maximal jump height [Hmax], peak power [Pmax] and peak force [Fmax]) can be obtained with a comparable or higher magnitude and reliability when the $S J$ is performed from the self-preferred knee angle $\left(S J_{\text {pref }}\right)$ compared to the SJ performed from a fixed initial knee angle (e.g., SJ from a $90^{\circ}$ knee angle; SJ90). However, although some studies have explored the effect of the knee angle (or squat depth) on CMJ performance (Gheller et al., 2015; Kirby et al., 2011; McBride et al., 2010; Sanchez-Sixto et al., 2018), no evidence exists so far with respect to the comparison of the reliability of the outcomes when the $\mathrm{CMJ}$ is performed from different knee angles or when KR is provided. Therefore, it would be of interest to determine the 
consistency of the mechanical variables obtained during the SJ and CMJ when the KR is provided in combination with the use of the self-preferred knee angle.

To address the gaps identified in the literature, we assessed the effect of KR on the mechanical variables collected with a force platform during the SJ and CMJ exercises performed both from a $90^{\circ}$ (SJ90 and CMJ90) and a self-preferred knee angle ( $\mathrm{SJ}_{\text {pref }}$ and $\mathrm{CMJ}_{\text {pref }}$ ). The objective of the present study was to determine whether the provision of KR can increase the magnitude and reliability of the aforementioned performance variables commonly reported during vertical jump testing procedures. We hypothesised that the provision of KR would increase the magnitude of the mechanical variables (i.e., higher performance). However, due to the lack of previous studies, we did not formulate any hypothesis regarding the effect of KR on the reliability of the variables. The findings of the present study are expected to contribute to the refinement of vertical jump testing procedures through the analysis of the effect of KR on the consistency of vertical jumps.

\section{Method \\ Participants}

Sixteen healthy young adults participated in this study (mean \pm standard deviation [SD]: 10 men [age $=26.4 \pm 7.0$ years; body mass $=75.8 \pm 9.6 \mathrm{~kg}$; height $=1.76 \pm 0.06 \mathrm{~m}$ ], and six women [age $=24.5 \pm 6.2$ years; body mass $=60.1 \pm 4.8 \mathrm{~kg}$; height $=1.63 \pm 0.07 \mathrm{~m}$ ]). All participants were physically active (physical exercise [hours per week] $=6.3 \pm 3.1$ for men and $5.4 \pm 2.6$ for women). All participants were free of recent injuries that could compromise vertical jump performance. Participants were excluded if they were unable to perform a SJ from a knee angle of $90^{\circ}$. They were instructed to avoid any strenuous exercises two days before each testing session. The study was approved by Institutional Ethical Committee of the University of Granada and the participants were informed of the benefits and risks of the investigation prior to signing an institutionally approved informed consent document to participate in the study.

\section{Experimental design}

A cross-sectional study was carried out to investigate the effect of providing KR on jumping performance and consistency during vertical jump testing procedures. Participants came to the laboratory on four separate occasions during two consecutive weeks. Two sessions were performed each week with at least 48 hours between sessions. The sessions were performed in a randomised order and consisted of (I) SJ performed without KR, (II) SJ performed with KR, (III) CMJ performed without KR, and (IV) CMJ performed with KR. Jump height (i.e., KR) was displayed on a screen immediately after each jump. Six jumps were randomly performed on each session: three trials from a $90^{\circ}$ knee angle and three trials from the self-preferred knee angle. The two jumps with higher jump height performance of each knee angle instruction were used for reliability analyses, and the average value of these two trials were used for the magnitude comparisons. All sessions were performed at the same time of the day for each participant ( \pm 1 hour) and under similar environmental conditions $\left(\sim 22^{\circ} \mathrm{C}\right.$ and $\sim 60 \%$ humidity). 


\section{Testing procedures}

Height (stadiometer Seca 202, Seca Ltd., Hamburg, Germany) and body mass (TBF300A, Tanita corporation of America Inc., Arlington Heights, IL, USA) were assessed at the beginning of the first testing session. The $90^{\circ}$ knee angle was determined with a manual goniometer during the first testing session, and an elastic cord was positioned parallel to the ground to make contact with the participants' glutei when they reached a $90^{\circ}$ knee angle (Chiu, Schilling, Fry \& Weiss, 2004). The elastic cord was only used during the standardised jumps (i.e., SJ90 and CMJ90). The warm-up consisted of five minutes of jogging, joint mobility exercises, and five progressive vertical jumps. Thereafter, the six maximal vertical jumps were performed separated by one minute. The characteristics of the four jump types evaluated are described below:

- Standardised SJ (SJ90): Participants were required to squat in a controlled manner until touching the elastic cord individually positioned to indicate the $90^{\circ}$ knee flexion and, after maintaining this static position for two seconds, they performed the propulsive phase with the instruction of jumping as high as possible.

- Self-preferred $S J\left(S J_{\text {pref }}\right)$ : Participants were required to squat in a controlled manner until reaching their self-preferred knee flexion and, after maintaining this static position for two seconds, they performed the propulsive phase with the instruction of jumping as high as possible.

- Standardised CMJ (CMJ90): Participants were required to perform a fast countermovement jump with a $90^{\circ}$ knee flexion angle and jump as high as possible. It should be noted that five seconds before each jump, participants were required to squat in a controlled manner until touching the elastic cord to have the feeling of their $90^{\circ}$ knee angle position.

- Self-preferred $C M J\left(C M J_{\text {pref }}\right)$ : Participants were required to perform a fast countermovement jump with their self-preferred knee angle and jump as high as possible.

All jumps were performed with the hands on the hips. Participants were instructed to jump as high as possible immediately before performing each jump. The only difference between the two sessions conducted with the same exercise (i.e., SJ and CMJ) is that in one session participants received KR and in the other session no KR was provided (i.e., Control condition). Jump height, which was estimated from the flight time by means of an infrared platform (Optojump, Microgate, Bolzano, Italy), was provided as KR to the participants right after performing each jump on a screen that was placed in front of the participants.

\section{Measurement equipment and data analysis}

All jumps were performed on a force platform (Dinascan/IBV, Biomechanics Institute of Valencia, Valencia, Spain) that sampled the vertical ground reaction force (vGRF) at $1,000 \mathrm{~Hz}$. Before each jump, participants were stationary on the centre of the force platform over three seconds. Body weight and the SD of the weighing phase were determined using the last second preceding the onset of the movement (Moir et al., 2005). The jump analysis began $30 \mathrm{~ms}$ before the instant in which the vGRF was higher (SJ) or lower (CMJ) than the body weight plus $5 \mathrm{SD}$ of the weighting phase (Owen et al., 2014; Perez-Castilla et al., 2019). The start of the propulsive phase for the CMJ was 
defined as the first time instant when the vertical velocity of the centre-of-mass was positive (Chavda et al., 2018). Vertical acceleration was calculated as the net vGRF divided by body mass. Vertical velocity of the centre-of-mass was determined by integrating acceleration with respect to time using the trapezoidal rule (Linthorne, 2001). Vertical power was calculated as the product of force and velocity at each time point. Mean (i.e., values averaged throughout the propulsive phase of the jump) and peak (i.e., maximum instantaneous values achieved over the propulsive phase of the jump) values of force, velocity and power were the dependent variables of the present study. A custommade Microsoft Excel ${ }^{\circ}$ spreadsheet (Microsoft Corporations, Redmond, Washington, USA) was used to calculate the mean and peak values of force, velocity and power (Chavda et al., 2018).

\section{Statistical analyses}

Descriptive values of all dependent variables (peak and mean values of force, velocity and power) are presented as means and SD. The normal distribution of the variables was confirmed by the Shapiro-Wilk test $(p>0.05)$. A three-way repeated measures (exercise [SJ and CMJ] $\mathrm{x}$ knee angle [ $90^{\circ}$ and self-preferred] $\mathrm{x}$ feedback [KR and Control]) was applied separately to each dependent variable. Paired samples $t$-tests were used to compare the magnitude of the variables between the feedback conditions separately for each exercise and knee angle. The typical error of measurement was expressed in relative terms through coefficient of variation (CV) whilst the relative agreement was determined using intraclass correlation coefficient (ICC; model 3.1). For all statistics the corresponding $95 \%$ confidence interval were incorporated into the analysis. The following criteria were used to determine acceptable $(\mathrm{CV} \leq 10 \%$, ICC $\geq 0.80)$ and high $(\mathrm{CV} \leq 5 \%$, ICC $\geq$ 0.90) reliability (James et al., 2017). The ratio between two CVs was used to compare the reliability of each variable between the feedback conditions separately for each exercise and knee angle. The smallest important ratio of CVs was considered to be higher than 1.15 (Fulton et al., 2009). The reliability analysis was performed by means of a custom spreadsheet (Hopkins, 2000a), while SPSS (version 22.0: SPSS, Inc., Chicago, IL, USA) was used for the remaining analyses. Alpha was set at 0.05 .

\section{Results}

The main effect of the feedback condition was significant for all variables due to a higher performance when the participants received KR (Table 1). The exercise $\times$ feedback interaction was only significant for peak force $(p=0.014)$ with a higher performance observed for the CMJ but not for the SJ when receiving KR. The knee angle $\times$ feedback interaction was not statistically significant (i.e. receiving $\mathrm{KR}$ is not affected by the knee angle instruction). Pairwise comparisons revealed a comparable (12 out of 24 comparisons; $p \geq 0.05$ ) or higher (12 out of 24 comparisons; $p<0.05$ ) performance when the participants received KR compared to the Control condition (i.e., no KR) (Figure 1). The self-preferred knee angle promoted a comparable (peak and mean force and peak power; $p \geq 0.05$ ) or higher (peak and mean velocity and mean power; $p<0.05$ ) performance than the standardised $90^{\circ}$ knee angle. 

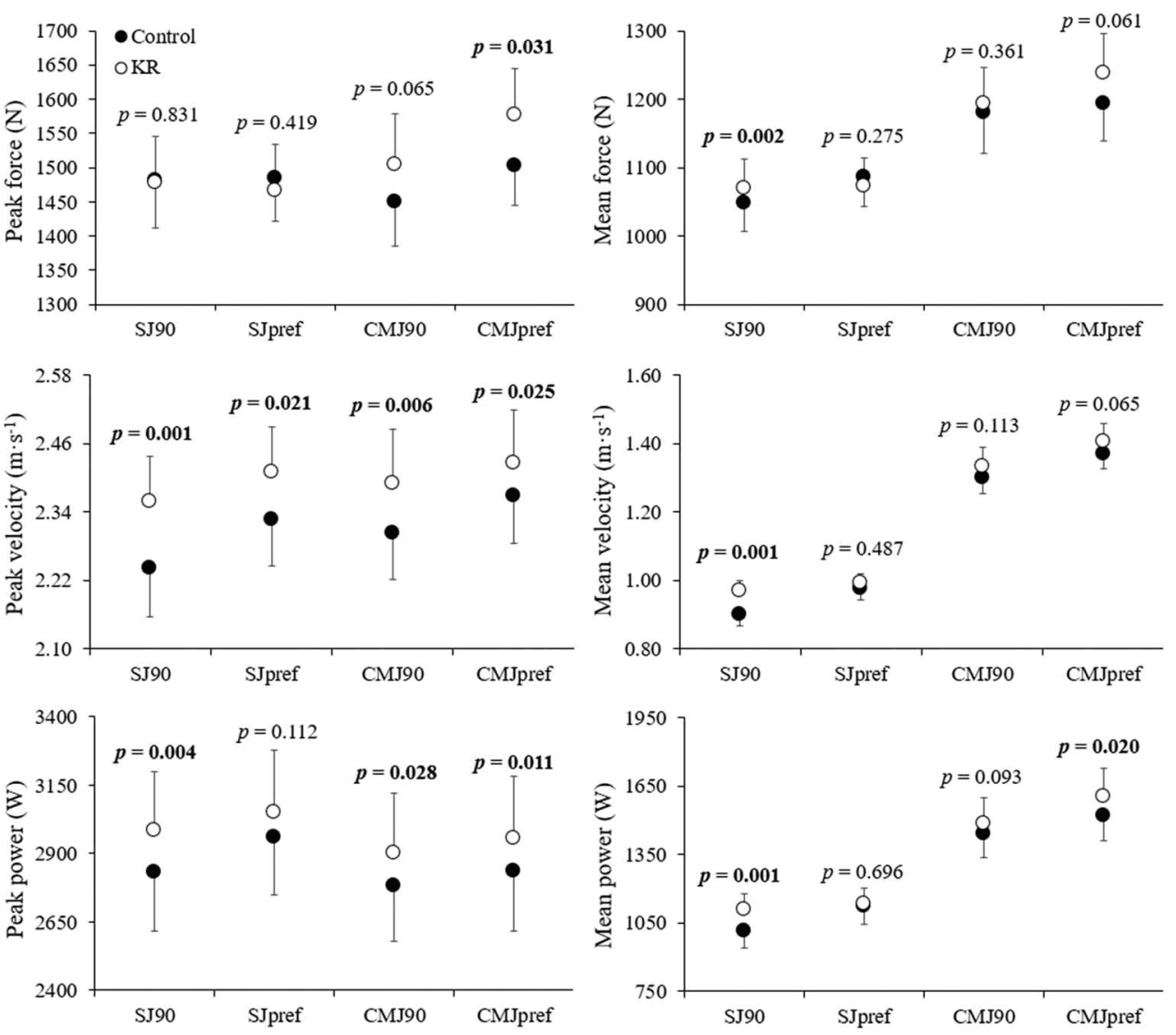

Figure 1. Comparison of peak force (upper-left panel), mean force (upper-right panel), peak velocity (middle-left panel), mean velocity (middle-right panel), peak power (lower-left panel) and mean power (lower-right panel) between the jumps performed with knowledge of results (KR) and without KR (control). $\mathrm{SJ} 90$, squat jump performed from a $90^{\circ}$ knee angle; $\mathrm{SJ}_{\text {pref, }}$ squat jump performed from the self-preferred knee angle; CMJ90, countermovement jump performed from a $90^{\circ}$ knee angle; $\mathrm{CMJ}_{\text {pref, }}$, countermovement jump performed from the self-preferred knee angle. Errors bars depict the standard error.

Table 1. Three-way repeated measures analysis of variance performed to compare the magnitude of vertical jump performance variables.

\begin{tabular}{|c|c|c|c|c|c|}
\hline \multirow[b]{2}{*}{ Variable } & \multirow[b]{2}{*}{ Jump type } & \multicolumn{2}{|c|}{ Feedback condition } & \multirow[b]{2}{*}{ Main effects } & \multirow[b]{2}{*}{ Interactions } \\
\hline & & Control & $\mathrm{KR}$ & & \\
\hline \multirow[t]{4}{*}{ Peak force $(\mathrm{N})$} & SJ90 & $1480 \pm 276$ & $1477 \pm 272$ & $\mathbf{E}: p=0.170$ & $\mathbf{E} \times \mathbf{A}: p=0.067$ \\
\hline & $S J_{\text {pref }}$ & $1484 \pm 252$ & $1466 \pm 275$ & A: $p=0.119$ & $\mathbf{E} \times \mathbf{F}: p=0.014$ \\
\hline & CMJ90 & $1449 \pm 256$ & $1504 \pm 294$ & $\mathbf{F}: p=0.046$ & $\mathbf{A} \times \mathbf{F}: p=0.942$ \\
\hline & $\mathrm{CMJ}_{\text {pref }}$ & $1503 \pm 236$ & $1578 \pm 269$ & & $\mathbf{E} \times \mathbf{A} \times \mathbf{F}: p=0.424$ \\
\hline \multirow[t]{4}{*}{ Mean force $(\mathrm{N})$} & SJ90 & $1047 \pm 166$ & $1069 \pm 171$ & E: $p<0.001$ & $\mathbf{E} \times \mathbf{A}: p=0.542$ \\
\hline & $S J_{\text {pref }}$ & $1086 \pm 170$ & $1072 \pm 167$ & A: $p=0.063$ & $\mathbf{E} \times \mathbf{F}: p=0.141$ \\
\hline & CMJ90 & $1180 \pm 232$ & $1193 \pm 210$ & $\mathbf{F}: p=0.037$ & $\mathbf{A} \times \mathbf{F}: p=0.865$ \\
\hline & $\mathrm{CMJ}_{\text {pref }}$ & $1194 \pm 224$ & $1238 \pm 235$ & & $\mathbf{E} \times \mathbf{A} \times \mathbf{F}: p=0.022$ \\
\hline \multirow[t]{4}{*}{ Peak velocity $\left(\mathrm{m} \cdot \mathrm{s}^{-1}\right)$} & SJ90 & $2.24 \pm 0.34$ & $2.36 \pm 0.32$ & $\mathbf{E}: p=0.108$ & $\mathbf{E} \times \mathbf{A}: p=0.524$ \\
\hline & $S J_{\text {pref }}$ & $2.33 \pm 0.33$ & $2.41 \pm 0.32$ & A: $p=0.001$ & $\mathbf{E} \times \mathbf{F}: p=0.493$ \\
\hline & CMJ90 & $2.30 \pm 0.32$ & $2.39 \pm 0.38$ & $\mathbf{F}: p<0.001$ & $\mathbf{A} \times \mathbf{F}: p=0.163$ \\
\hline & $\mathrm{CMJ}_{\text {pref }}$ & $2.37 \pm 0.34$ & $2.43 \pm 0.37$ & & $\mathbf{E} \times \mathbf{A} \times \mathbf{F}: p=0.929$ \\
\hline
\end{tabular}

(Continued) 
Table 1. (Continued).

\begin{tabular}{|c|c|c|c|c|c|}
\hline \multirow[b]{2}{*}{ Variable } & \multirow[b]{2}{*}{ Jump type } & \multicolumn{2}{|c|}{ Feedback condition } & \multirow[b]{2}{*}{ Main effects } & \multirow[b]{2}{*}{ Interactions } \\
\hline & & Control & $\mathrm{KR}$ & & \\
\hline \multirow[t]{4}{*}{ Mean velocity $\left(\mathrm{m} \cdot \mathrm{s}^{-1}\right)$} & SJ90 & $0.90 \pm 0.13$ & $0.97 \pm 0.12$ & E: $p<0.001$ & $\mathbf{E} \times \mathbf{A}: p=0.379$ \\
\hline & $\mathrm{SJ}_{\text {pref }}$ & $0.97 \pm 0.13$ & $0.99 \pm 0.10$ & A: $p<0.001$ & $\mathbf{E} \times \mathbf{F}: p=0.690$ \\
\hline & CMJ90 & $1.30 \pm 0.18$ & $1.33 \pm 0.22$ & $\mathbf{F}: p=0.004$ & $\mathbf{A} \times \mathbf{F}: p=0.184$ \\
\hline & $\mathrm{CMJ}_{\text {pref }}$ & $1.37 \pm 0.18$ & $1.41 \pm 0.21$ & & $\mathbf{E} \times \mathbf{A} \times \mathbf{F}: p=0.136$ \\
\hline \multirow[t]{4}{*}{ Peak power $(\mathrm{W})$} & SJ90 & $2832 \pm 862$ & $2983 \pm 869$ & $\mathbf{E}: p=0.026$ & $\mathbf{E} \times \mathbf{A}: p=0.327$ \\
\hline & $\mathrm{SJ}_{\text {pref }}$ & $2961 \pm 849$ & $3052 \pm 899$ & A: $p=0.061$ & $\mathbf{E} \times \mathbf{F}: p=0.981$ \\
\hline & CMJ90 & $2781 \pm 813$ & $2900 \pm 873$ & $\mathbf{F}: p<0.001$ & $\mathbf{A} \times \mathbf{F}: p=0.489$ \\
\hline & $\mathrm{CMJ}_{\text {pref }}$ & $2836 \pm 869$ & $2956 \pm 903$ & & $\mathbf{E} \times \mathbf{A} \times \mathbf{F}: p=0.397$ \\
\hline \multirow[t]{4}{*}{ Mean power $(\mathrm{W})$} & SJ90 & $1011 \pm 289$ & $1106 \pm 293$ & $\mathbf{E}: p<0.001$ & $\mathbf{E} \times \mathbf{A}: p=0.409$ \\
\hline & $S J_{\text {pref }}$ & $1121 \pm 307$ & $1134 \pm 270$ & A: $p<0.001$ & $\mathbf{E} \times \mathbf{F}: p=0.708$ \\
\hline & CMJ90 & $1440 \pm 417$ & $1484 \pm 449$ & $\mathbf{F}: p=0.001$ & $\mathbf{A} \times \mathbf{F}: p=0.533$ \\
\hline & $\mathrm{CMJ}_{\text {pref }}$ & $1519 \pm 442$ & $1605 \pm 494$ & & $\mathbf{E} \times \mathbf{A} \times \mathbf{F}: p=0.038$ \\
\hline
\end{tabular}

Data are mean \pm standard deviation. $\mathrm{S} J 90$, squat jump performed from a $90^{\circ}$ knee angle; $\mathrm{SJ} J_{\text {pref, }}$ squat jump performed from the self-preferred knee angle; CMJ90, countermovement jump performed from a $90^{\circ}$ knee angle; $C M J_{\text {pref }}$, countermovement jump performed from the self-preferred knee angle; $E$, exercise (SJ and CMJ); $A$, knee angle ( $90^{\circ}$ and self-preferred; F, Feedback condition (Control and KR).

A high reliability was generally observed for all variables regardless of the exercise, knee angle and feedback condition $(\mathrm{CV} \leq 5.62 \%$, ICC $\geq 0.95)$ (Table 2). No systematic differences in reliability were observed between the jumps performed with $\mathrm{KR}$ $(\mathrm{CV}=3.04 \pm 1.49 \%$, ICC $=0.97 \pm 0.04)$ and the Control condition (i.e., no KR) $(\mathrm{CV}=3.00 \pm 1.38 \%$, ICC $=0.97 \pm 0.03)$. Of note is that the reliability was higher in 6 out of 24 comparisons for the jumps performed with KR, no differences between the feedback conditions were obtained in 12 out of 24 comparisons, and in 6 out of 24 comparisons the reliability was higher for the jumps performed without KR (Figure 2). No differences in reliability were observed between the standardised $90^{\circ}$ knee angle $(\mathrm{CV}=3.13 \pm 1.56 \%$, ICC $=0.97 \pm 0.03)$ and self-preferred knee angle $(\mathrm{CV}=2.91 \pm 1.29 \%, \mathrm{ICC}=0.97 \pm 0.04)$ nor between the SJ $(\mathrm{CV}=3.00 \pm 1.56 \%$, $\mathrm{ICC}=0.97 \pm 0.05)$ and $\mathrm{CMJ}(\mathrm{CV}=3.04 \pm 1.29 \%, \mathrm{ICC}=0.98 \pm 0.02)$.

Table 2. Reliability of vertical jump performance variables.

\begin{tabular}{|c|c|c|c|c|}
\hline Variable & Jump type & Feedback & CV\% (95\% Cl) & ICC (95\% Cl) \\
\hline \multirow[t]{8}{*}{ Peak force } & SJ90 & Control & $2.76(2.04,4.27)$ & $0.98(0.95,0.99)$ \\
\hline & SJ90 & $\mathrm{KR}$ & $2.16(1.59,3.34)$ & $0.99(0.97,1.00)$ \\
\hline & $S J_{\text {pref }}$ & Control & $1.94(1.43,3.00)$ & $0.99(0.97,1.00)$ \\
\hline & $S J_{\text {pref }}$ & $\mathrm{KR}$ & $2.10(1.55,3.25)$ & $0.99(0.97,1.00)$ \\
\hline & CMJ90 & Control & $1.84(1.36,2.85)$ & $0.99(0.97,1.00)$ \\
\hline & CMJ90 & $\mathrm{KR}$ & $3.01(2.23,4.66)$ & $0.98(0.94,0.99)$ \\
\hline & $\mathrm{CMJ}_{\text {pref }}$ & Control & $3.89(2.88,6.03)$ & $0.95(0.86,0.98)$ \\
\hline & $C M J_{\text {pref }}$ & $\mathrm{KR}$ & $3.26(2.41,5.05)$ & $0.97(0.91,0.99)$ \\
\hline \multirow[t]{8}{*}{ Mean force } & SJ90 & Control & $1.78(1.31,2.75)$ & $0.99(0.97,1.00)$ \\
\hline & SJ90 & $\mathrm{KR}$ & $1.89(1.40,2.93)$ & $0.99(0.97,1.00)$ \\
\hline & $S J_{\text {pref }}$ & Control & $2.60(1.92,4.02)$ & $0.98(0.94,0.99)$ \\
\hline & $\mathrm{SJ}_{\text {pref }}$ & $\mathrm{KR}$ & $2.08(1.53,3.21)$ & $0.98(0.96,0.99)$ \\
\hline & CMJ90 & Control & $2.02(1.49,3.13)$ & $0.99(0.97,1.00)$ \\
\hline & CMJ90 & $\mathrm{KR}$ & $2.70(1.99,4.17)$ & $0.98(0.94,0.99)$ \\
\hline & $\mathrm{CMJ}_{\text {pref }}$ & Control & $2.37(1.75,3.67)$ & $0.99(0.96,1.00)$ \\
\hline & $C M J_{\text {pref }}$ & KR & $2.29(1.69,3.54)$ & $0.99(0.97,1.00)$ \\
\hline
\end{tabular}


Table 2. (Continued).

\begin{tabular}{|c|c|c|c|c|}
\hline Variable & Jump type & Feedback & CV\% (95\% Cl) & ICC (95\% Cl) \\
\hline \multirow[t]{8}{*}{ Peak velocity } & SJ90 & Control & $1.78(1.32,2.76)$ & $0.99(0.97,1.00)$ \\
\hline & SJ90 & $\mathrm{KR}$ & $1.11(0.82,1.71)$ & $0.99(0.98,1.00)$ \\
\hline & $S J_{\text {pref }}$ & Control & $1.59(1.18,2.47)$ & $0.99(0.97,1.00)$ \\
\hline & $\mathrm{SJ}_{\text {pref }}$ & $\mathrm{KR}$ & $1.36(1.00,2.10)$ & $0.99(0.97,1.00)$ \\
\hline & CMJ90 & Control & $1.28(0.94,1.97)$ & $0.99(0.98,1.00)$ \\
\hline & CMJ90 & $\mathrm{KR}$ & $1.71(1.27,2.65)$ & $0.99(0.97,1.00)$ \\
\hline & $\mathrm{CMJ}_{\text {pref }}$ & Control & $1.31(0.97,2.03)$ & $0.99(0.98,1.00)$ \\
\hline & $\mathrm{CMJ}_{\text {pref }}$ & $\mathrm{KR}$ & $1.79(1.33,2.78)$ & $0.99(0.97,1.00)$ \\
\hline \multirow[t]{8}{*}{ Mean velocity } & SJ90 & Control & $5.06(3.74,7.83)$ & $0.90(0.74,0.96)$ \\
\hline & SJ90 & KR & $5.05(3.73,7.82)$ & $0.87(0.66,0.95)$ \\
\hline & $\mathrm{SJ}_{\text {pref }}$ & Control & $4.68(3.46,7.24)$ & $0.90(0.75,0.97)$ \\
\hline & $\mathrm{SJ}_{\text {pref }}$ & $\mathrm{KR}$ & $4.89(3.61,7.57)$ & $0.82(0.56,0.93)$ \\
\hline & CMJ90 & Control & $4.93(3.64,7.63)$ & $0.90(0.74,0.96)$ \\
\hline & CMJ90 & $\mathrm{KR}$ & $4.75(3.51,7.35)$ & $0.93(0.82,0.98)$ \\
\hline & $C M J_{\text {pref }}$ & Control & $2.56(1.89,3.95)$ & $0.97(0.91,0.99)$ \\
\hline & $C M J_{\text {pref }}$ & $\mathrm{KR}$ & $3.92(2.89,6.06)$ & $0.94(0.84,0.98)$ \\
\hline \multirow{8}{*}{ Peak power } & SJ90 & Control & $3.15(2.33,4.88)$ & $0.99(0.97,1.00)$ \\
\hline & SJ90 & $\mathrm{KR}$ & $1.41(1.04,2.17)$ & $1.00(0.99,1.00)$ \\
\hline & $\mathrm{SJ}_{\text {pref }}$ & Control & $1.94(1.44,3.01)$ & $1.00(0.99,1.00)$ \\
\hline & $\mathrm{SJ}_{\text {pref }}$ & $\mathrm{KR}$ & $1.78(1.31,2.75)$ & $1.00(0.99,1.00)$ \\
\hline & CMJ90 & Control & $2.67(1.97,4.13)$ & $0.99(0.98,1.00)$ \\
\hline & CMJ90 & $\mathrm{KR}$ & $2.55(1.88,3.95)$ & $0.99(0.98,1.00)$ \\
\hline & $C M J_{\text {pref }}$ & Control & $2.42(1.79,3.75)$ & $0.99(0.98,1.00)$ \\
\hline & $\mathrm{CMJ}_{\text {pref }}$ & $\mathrm{KR}$ & $2.24(1.65,3.46)$ & $1.00(0.99,1.00)$ \\
\hline \multirow{8}{*}{ Mean power } & SJ90 & Control & $4.88(3.61,7.56)$ & $0.98(0.93,0.99)$ \\
\hline & SJ90 & $\mathrm{KR}$ & $5.29(3.91,8.18)$ & $0.97(0.91,0.99)$ \\
\hline & $S J_{\text {pref }}$ & Control & $5.17(3.82,8.01)$ & $0.97(0.92,0.99)$ \\
\hline & $\mathrm{SJ}_{\text {pref }}$ & $\mathrm{KR}$ & $5.52(4.08,8.55)$ & $0.95(0.88,0.98)$ \\
\hline & CMJ90 & Control & $5.62(4.16,8.71)$ & $0.97(0.91,0.99)$ \\
\hline & CMJ90 & KR & $5.60(4.14,8.67)$ & $0.97(0.92,0.99)$ \\
\hline & $\mathrm{CMJ}_{\text {pref }}$ & Control & $3.68(2.72,5.69)$ & $0.99(0.96,1.00)$ \\
\hline & $\mathrm{CMJ}_{\text {pref }}$ & $\mathrm{KR}$ & $4.52(3.34,6.99)$ & $0.98(0.95,0.99)$ \\
\hline
\end{tabular}

\section{Discussion and implications}

This study was designed to elucidate whether the provision of KR based on jump height performance could increase the magnitude (i.e., performance) and reliability (i.e., consistency) of the mechanical variables commonly assessed during vertical jump testing procedures. In line with previous studies, vertical jump performance was increased when the participants received KR. However, the most novel finding of the present study was that the provision of KR did not affect the reliability of the variables collected the vertical jumps. These results were consistent for both exercises (SJ and $\mathrm{CMJ}$ ) and knee angle instructions (standardised at $90^{\circ}$ and self-preferred). Therefore, the provision of KR should be recommended during vertical jump testing procedures to enhance the performance of vertical jumps, but it does not reduce the variability between jumps.

In line with our hypothesis, a higher performance was observed for the KR compared to the control condition regardless of the knee angle instruction (standardised and selfpreferred) and exercise (SJ and CMJ). These findings are in consent with other studies that have observed a benefit of KR on jumping performance (Keller et al., 2014, 2015; 

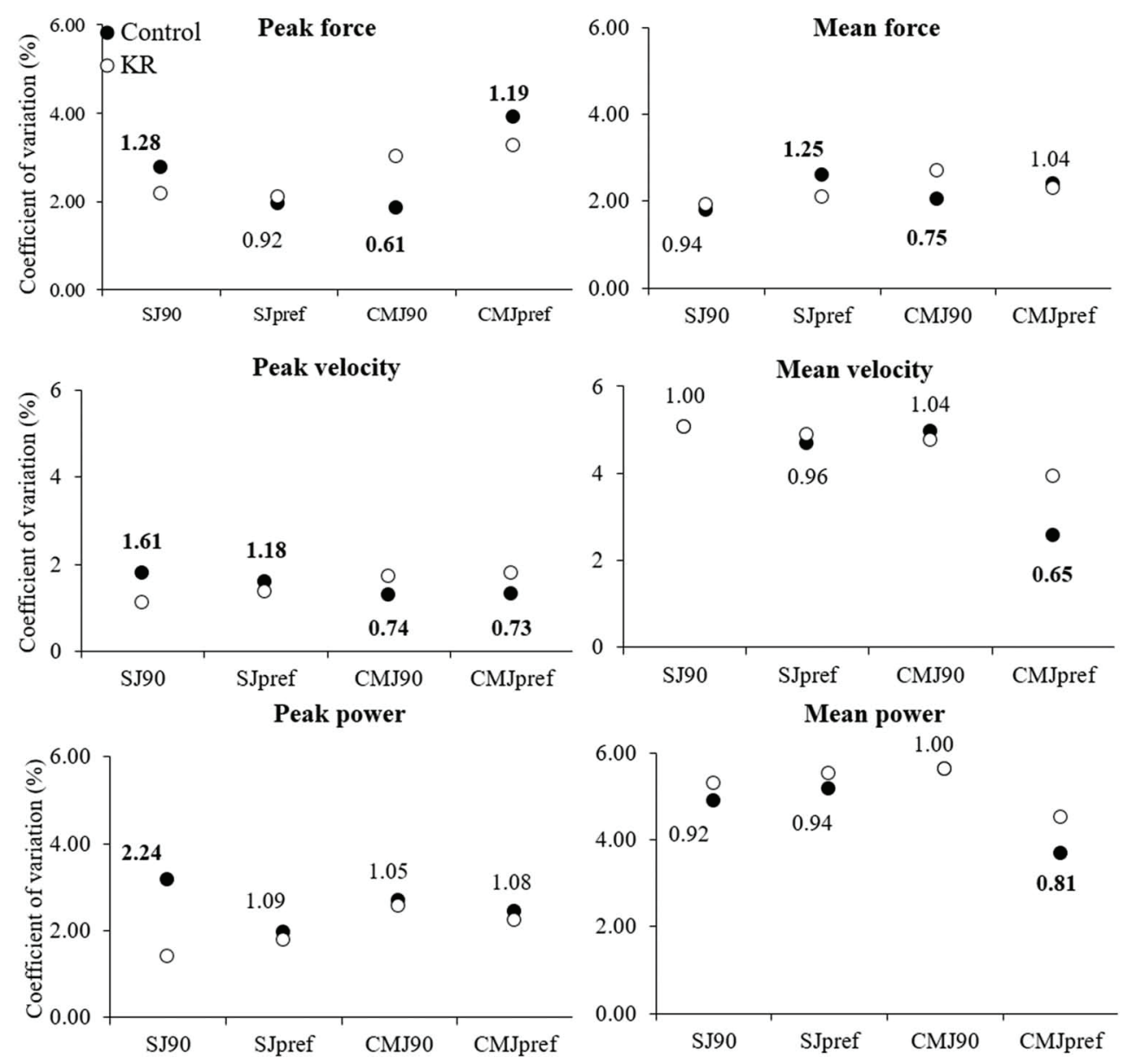

Figure 2. Reliability comparisons between the jumps performed with knowledge of results (KR) and without KR (control) for peak force (upper-left panel), mean force (upper-right panel), peak velocity (middle-left panel), mean velocity (middle-right panel), peak power (lower-left panel) and mean power (lower-right panel). Numbers indicate the ratio between two coefficient of variation (CV) (CV ratio $=\mathrm{CV}$ control/CV KR). Bold numbers indicate significant differences (CV ratio $>1.15$ [higher consistency for KR]; CV ratio < 0.87 [higher consistency for control]).

Nagata et al., 2018; Vanderka et al., 2018). It has been reported that different types of KR (e.g., peak velocity, power output, jump height) can be effective at enhancing vertical jump performance (Keller et al., 2015; Vanderka et al., 2018; Weakley et al., 2019). Even though authors could not draw final conclusions about the underlying mechanisms of the higher performance using the KR condition (Keller et al., 2015), increased performance may be attained by an increase in motivation (Weakley et al., 2019; Salmon et al., 1984). Irrespective of the mechanism, the findings of this study are in line with studies that have emphasised the importance of providing KR during training to enhance vertical jump performance (Randell et al., 2011a).

The reliability of the mechanical variables was high and not systematically affected by the exercise (SJ and CMJ), knee angle (standardised and self-preferred) or feedback instruction 
(KR and Control). These results are supported by the small number of studies that have compared the reliability of the variables obtained during vertical jump testing procedures between the standardised and self-preferred knee angles (Argus \& Chapman, 2014; Janicijevic et al., 2019; Petronijevic et al., 2018). Therefore, from a reliability standpoint, the SJ and CMJ may be performed from the self-preferred knee angle since no differences in reliability outcomes were observed between the knee angle instructions (i.e., standardised vs. self-preferred), albeit the self-preferred knee angle does simplify the testing procedure. To date, only one study has investigated the possible benefits of providing KR on the reliability of the variables collected during vertical jumps (Randell et al., 2011b). Randell et al. (2011b) assessed the betweensession reliability of peak velocity during training sessions that consisted of 4 sets of 8 repetitions of SJs that were performed with an external load of $40 \mathrm{~kg}$ from a $90^{\circ}$ knee flexion. In this study, a higher consistency for the KR condition was observed. It should be noted that the results observed in the present study for the SJ90 support the findings of Randell et al. (2011b). However, in the other test conditions we could not confirm their result and found similar consistency in jumps with and without KR. Therefore, from a reliability standpoint, the provision of KR does not seem to be an important factor to be considered during vertical jump testing. However, we recommend the provision of KR due to the higher mechanical outputs recorded which are likely caused by an increase in participants' motivation (Weakley et al., 2019; Salmon et al., 1984).

The magnitude of the mechanical variables was reported to be similar or higher when selecting self-preferred knee angles compared to a standardised knee angle for both SJs and CMJs. Indeed, it has been reported that both SJ and CMJ performance is affected by the position at the beginning of the propulsion phase (Gheller et al., 2015; McBride et al., 2010; Mitchell et al., 2017; Petronijevic et al., 2018). For example, Gheller et al. (2015) and Janicijevic et al. (2019) observed higher values of peak power, but not peak force, for the $S J_{\text {pref }}$ compared to the SJ90. Similarly, Petronijevic et al. (2018) reported higher values of both peak power and peak force for the $S J_{\text {pref }}$ compared to the $S J 90$. Concerning the CMJ, Gheller et al. (2015) documented comparable or higher performance for the $\mathrm{CMJ}_{\text {pref }}$ compared to the CMJ90. Regarding the reliability of the variables, our results are in line with the findings of Argus and Chapman (2014) and Petronijevic et al. (2018) since the reliability was not systematically affected by the knee angle instruction or the exercise. Based on these results, the $\mathrm{CMJ}_{\text {pref }}$ could be recommended due to its simplicity and higher ecological validity as the reliability of the mechanical variables was not compromised, while their magnitude was comparable or higher.

Even though this is the first study that has explored whether the provision of KR could increase the magnitude and reliability of SJ and CMJ performance variables, several limitations should be acknowledged. The main limitation is that the participants tested in the present study had limited experience with vertical jump testing procedures. Therefore, it remains to be elucidated whether the increase in vertical jump performance observed in the present study following the KR condition could also be extrapolated to experienced athletes. In addition, future studies should elucidate whether the provision of KR has different effects on men and women since the small number of women recruited for the present study did not allow us to conduct a between-sex analysis. 


\section{Conclusion}

The provision of jump height performance (i.e., KR) is an effective method to increase the magnitude of the main mechanical variables commonly assessed with force platforms during vertical jump testing procedures. The enhancement in performance was observed for all variables during the SJ and CMJ exercises with the only exception of the peak force recorded during the SJ. Similarly, a higher performance for the KR condition was observed regardless of if the jumps were performed from a standardised $90^{\circ}$ knee angle or from the self-preferred knee angle. The novel finding of the present study is that the reliability of the mechanical variables was not affected by the feedback condition. Based on these results, it can be concluded that the provision of jump height feedback during vertical jump testing procedures is effective at enhancing vertical jump performance but, importantly, it does not affect the reliability of the outcome measures.

\section{Acknowledgments}

We would like to thank all participants that voluntary participated in this study.

\section{Disclosure statement}

No potential conflict of interest was reported by the author(s).

\section{ORCID}

Amador García-Ramos (D) http://orcid.org/0000-0003-0608-8755

Alejandro Pérez-Castilla (iD) http://orcid.org/0000-0001-5535-2087

\section{References}

Argus, C., \& Chapman, D. W. (2014). The effect of initial knee angle on the reliability of variables derived from a squat jump. Medicina Sportiva, 18, 125-130. doi:10.5604/17342260.1127307

Chavda, S., Bromley, T., Jarvis, P., Williams, S., Bishop, C., Turner, A. N., Lake, J., \& Mundy, P. D. (2018). Force-time characteristics of the countermovement jump. Strength and Conditioning Journal, 40, 67-77. doi:10.1519/SSC.0000000000000353

Chiu, L. Z. F., Schilling, B. K., Fry, A. C., \& Weiss, L. W. (2004). Measurement of resistance exercise force expression. Journal of Applied Biomechanics, 20, 204-212. doi:10.1123/ jab.20.2.204

Duthie, G. M., Young, W. B., \& Aitken, D. A. (2002). The acute effects of heavy loads on jump squat performance: An evaluation of the complex and contrast methods of power development. Journal of Strength and Conditioning Research, 16, 530-538. doi: 10.1519/1533-4287(2002) 016<0530:TAEOHL >2.0.CO;2

Fulton, S. K., Pyne, D., Hopkins, W., \& Burkett, B. (2009). Variability and progression in competitive performance of Paralympic swimmers. Journal of Sports Sciences, 27, 535-539. doi:10.1080/02640410802641418

Gheller, R. G., Dal Pupo, J., Ache-Dias, J., Detanico, D., Padulo, J., \& Dos Santos, S. G. (2015). Effect of different knee starting angles on intersegmental coordination and performance in vertical jumps. Human Movement Science, 42, 71-80. doi:10.1016/j.humov.2015.04.010

Hopkins, W. (2000a). Calculations for reliability (Excel spreedsheet), a new view of statistics. Retrieved June 15, 2019, from http://www.sportsci.org/resource/stats/relycalc.html 
Hopkins, W. (2000b). Measures of reliability in sports medicine and science. Sports Medicine, 30, 1-15. doi:10.2165/00007256-200030010-00001

Impellizzeri, F. M., Rampinini, E., Maffiuletti, N., \& Marcora, S. M. (2007). A vertical jump force test for assessing bilateral strength asymmetry in athletes. Medicine \& Science in Sports \& Exercise, 39, 2044-2050. doi:10.1249/mss.0b013e31814fb55c

James, L. P., Roberts, L. A., Haff, G. G., Kelly, V. G., \& Beckman, E. M. (2017). Validity and reliability of a portable isometric mid-thigh clean pull. Journal of Strength and Conditioning Research, 31, 1378-1386. doi:10.1519/JSC.0000000000001201

Janicijevic, D., Knezevic, O. M., Mirkov, D. M., Pérez-Castilla, A., Petrovic, M., \& García-ramos, A. (2019). Magnitude and reliability of mechanical outputs obtained during loaded squat jumps performed from different knee angles. Sports Biomechanics. In press. doi:10.1080/ 14763141.2019.1618390

Keller, M., Lauber, B., Gehring, D., Leukel, C., \& Taube, W. (2014). Jump performance and augmented feedback: Immediate benefits and long-term training effects. Human Movement Science, 36, 177-189. doi:10.1016/j.humov.2014.04.007

Keller, M., Lauber, B., Gottschalk, M., \& Taube, W. (2015). Enhanced jump performance when providing augmented feedback compared to an external or internal focus of attention. Journal of Sports Sciences, 33, 1067-1075. doi:10.1080/02640414.2014.984241

Kirby, T. J., McBride, J. M., Haines, T. L., \& Dayne, A. M. (2011). Relative net vertical impulse determines jumping performance. Journal of Applied Biomechanics, 27, 207-214. doi:10.1123/ jab.27.3.207

Linthorne, N. P. (2001). Analysis of standing vertical jumps using a force platform. American Journal of Physics, 69, 1198-1204. doi:10.1119/1.1397460

Mandic, R., Jakovljevic, S., \& Jaric, S. (2015). Effects of countermovement depth on kinematic and kinetic patterns of maximum vertical jumps. Journal of Electromyography and Kinesiology, 25, 265-272. doi:10.1016/j.jelekin.2014.11.001

Markovic, G., Dizdar, D., Jukic, I., \& Cardinale, M. (2004). Reliability and factorial validity of squat and countermovement jump tests. Journal of Strength and Conditioning Research, 18, 551-555. doi:10.1519/1533-4287(2004)18<551:RAFVOS >2.0.CO;2

McBride, J. M., Kirby, T. J., Haines, T. L., \& Skinner, J. (2010). Relationship between relative net vertical impulse and jump height in jump squats performed to various squat depths and with various loads. International Journal of Sports Physiology and Performance, 5, 484-496. doi:10.1123/ijspp.5.4.484

Mitchell, L. J., Argus, C. K., Taylor, K. L., Sheppard, J. M., \& Chapman, D. W. (2017). The effect of initial knee angle on concentric-only squat jump performance. Research Quarterly for Exercise and Sport, 88, 184-192. doi:10.1080/02701367.2017.1293777

Moir, G., Sanders, R., Button, C., \& Glaister, M. (2005). The influence of familiarization on the reliability of force variables measured during unloaded and loaded vertical jumps. Journal of Strength and Conditioning Research, 19, 140-145. doi:10.1519/14803.1

Nagata, A., Doma, K., Yamashita, D., Hasegawa, H., \& Mori, S. (2018). The effect of augmented feedback type and frequency on velocity-based training-induced adaptation and retention. Journal of Strength and Conditioning Research. In press. doi:10.1519/JSC.0000000000002514

Owen, N. J., Watkins, J., Kilduff, L. P., Bevan, H. R., \& Bennett, M. A. (2014). Development of a criterion method to determine peak mechanical power output in a countermovement jump. Journal of Strength and Conditioning Research, 28, 1552-1558. doi:10.1519/JSC.0000000000000311

Perez-Castilla, A., Rojas, F. J., \& Garcia-Ramos, A. (2019). Assessment of unloaded and loaded squat jump performance with a force platform: Which jump starting threshold provides more reliable outcomes? Journal of Biomechanics, 92, 19-28. doi:10.1016/j.jbiomech.2019.05.022

Petronijevic, M. S., García-Ramos, A., Mirkov, D. M., Jaric, S., Valdevit, Z., \& Knezevic, O. M. (2018). Self-preferred initial position could be a viable alternative to the standard squat jump testing procedure. The Journal of Strength and Conditioning Research, 32, 3267-3275. doi:10.1519/JSC.0000000000002385

Randell, A. D., Cronin, J. B., Keogh, J. W., Gill, N. D., \& Pedersen, M. C. (2011a). Effect of instantaneous performance feedback during 6 weeks of velocity-based resistance training on 
sport-specific performance tests. Journal of Strength and Conditioning Research, 25, 87-93. doi:10.1519/JSC.0b013e3181fee634

Randell, A. D., Cronin, J. B., Keogh, J. W., Gill, N. D., \& Pedersen, M. C. (2011b). Reliability of performance velocity for jump squats under feedback and nonfeedback conditions. Journal of Strength and Conditioning Research, 25, 3514-3518. doi:10.1519/JSC.0b013e318216001f

Salmon, A. W., Schmidt, R. A., \& Walter, C. B. (1984). Knowledge of results and motor learning: A review and critical reappraisal. Psychological Bulletin, 95, 355-386. doi:10.1037/00332909.95.3.355

Sanchez-Sixto, A., Harrison, A. J., \& Floria, P. (2018). Larger countermovement increases the jump height of countermovement jump. Sports (Basel, Switzerland), 6, 131. doi:10.3390/ sports6040131

Simpson, J. D., Miller, B. L., O’Neal, E. K., Chander, H., \& Knight, A. C. (2018). Ground reaction forces during a drop vertical jump: Impact of external load training. Human Movement Science, 59, 12-19. doi:10.1016/j.humov.2018.03.011

Skurvydas, A., Jascaninas, J., \& Zachovajevas, P. (2000). Changes in height of jump, maximal voluntary contraction force and low-frequency fatigue after 100 intermittent or continuous jumps with maximal intensity. Acta Physiologica Scandinavica, 169, 55-62. doi:10.1046/j.1365201x.2000.00692.x

Vanderka, M., Bezák, A., Longová, K., Krčmár, M., \& Walker, S. (2018). Use of visual feedback during jump-squat training aids improvement in sport-specific tests in athletes. Journal of Strength and Conditioning Research. In press. doi:10.1519/JSC.0000000000002634

Vanrenterghem, J., Lees, A., Lenoir, M., Aerts, P., \& De Clercq, D. (2004). Performing the vertical jump: Movement adaptations for submaximal jumping. Human Movement Science, 22, $713-$ 727. doi:10.1016/j.humov.2003.11.001

Walchli, M., Ruffieux, J., Bourquin, Y., Keller, M., \& Taube, W. (2016). Maximizing performance: Augmented feedback, focus of attention, and/or reward? Medicine and Science in Sports and Exercise, 48, 714-719. doi:10.1249/MSS.0000000000000818

Weakley, J., Till, K., Sampson, J., Banyard, H., Leduc, C., Wilson, K., Roe, G., \& Jones, B. (2019). The effects of augmented feedback on sprint, jump, and strength adaptations in rugby union players following a four week training programme. International Journal of Sports Physiology and Performance, 14, 1205-1211. doi:10.1123/ijspp.2018-0523

Weakley, J. J., Wilson, K. M., Till, K., Read, D. B., Darrall-Jones, J., Roe, G., Phibbs, P. J., \& Jones, B. (2019). Visual feedback attenuates mean concentric barbell velocity loss, and improves motivation, competitiveness, and perceived workload in male adolescent athletes. Journal of Strength and Conditioning Research, 33, 2420-2425. doi:10.1519/JSC.0000000000002133 